\title{
TOTAL NONDIALYZABLE SOLIDS (TNDS) IN HUMAN URINE. III. A METHOD FOR SUBFRACTIONATION OF RS-1 SOLIDS *
}

\author{
By J. S. KING, JR., J. M. LITTLE, W. H. BOYCE and C. ARTOM \\ (From the Departments of Biochemistry, Urology, Physiology and Pharmacology, The Bow- \\ man Gray School of Medicine of Wake Forest College, Winston-Salem, \\ North Carolina.)
}

(Submitted for publication March 30, 1959; accepted May 14, 1959)

The total nondialyzable solids (TNDS) of normal human urine have been found to have an approximate composition of 47 per cent protides, 16.6 per cent glucides, 9.7 per cent sialic acid, 6.2 per cent hexosamine, 3.3 per cent lipids, 12.2 per cent bound water and 8.5 per cent ash (1). The mean TNDS excretion in two series of determinations has been found to be $433 \mathrm{mg}$. and $505 \mathrm{mg}$. per 24 hours, with a value of 472 (S.D. \pm 108 ) mg. per 24 hours for the combined series $(1,2)$. Methods have been described for separation of the TNDS into three reproducible fractions (2). Figure 1 is a flow sheet illustrating the technique and approximate percentage weight distribution of each fraction. Boundary electrophoretic studies, at $\mathrm{pH} 8.6$, have demonstrated the presence of concentration gradients in the RS-1 fraction which have mobilities closely approximating each of the gradients of normal blood plasma under similar conditions (3). The Cohn Method 10 for fractionation of plasma proteins has been modified by Lever and co-workers to permit separation of small quantities of plasma proteins (4). The present report concerns the application of this technique to the fractionation of RS-1 solids from normal human urine.

\section{MATERIALS AND METHODS}

Subjects. Ten to 12 subjects (seven male and five female) submitted 24 hour urine specimens, which were pooled daily for rapid processing (2).

Reagents. The reagents were prepared from stock solutions at room temperature and cooled to $-5^{\circ} \mathrm{C}$. immediately before use. The reagents $\mathrm{A}$ and $\mathrm{A}^{\prime}$ of Lever gave an initial precipitation medium of $\mathrm{pH} 5.8$. $\mathrm{\Gamma} / 2$ of 0.04 and 19 per cent ethanol when added to the requisite

* Supported by Public Health Service Grants A-259 and H-2820, National Institutes of Health, and by grants from Mary Reynolds Babcock Foundation and from the American Urological Research Foundation. amount of acid-citrate-dextrose (ACD) plasma. The aqueous solution of RS-1 urinary fraction was found to lack the buffering action of ACD plasma; hence, in order to achieve the above conditions for urinary RS-1, the reagents $A$ and $A^{\prime}$ of Lever and co-workers were combined to form Reagent I.

Reagent $I$. This reagent contained $250 \mathrm{ml} .95$ per cent ethanol, $20 \mathrm{ml}$. of $\mathrm{M}$ sodium acetate, $1.75 \mathrm{ml}$. of $\mathrm{M}$ acetic acid and water to make $1,000 \mathrm{ml}$. When necessary, the $\mathrm{pH}$ of this solution was adjusted to $\mathrm{pH} 5.80 \pm 0.05$ by addition of approximately $0.05 \mathrm{ml}$. of $10 \mathrm{M}$ acetic acid.

Zinc reagent. This reagent contained $54.8 \mathrm{Gm}$. of zinc acetate dihydrate dissolved in $500 \mathrm{ml}$. of water, to which $200 \mathrm{ml}$. of 95 per cent ethanol was added and then sufficient water to make $1,000 \mathrm{ml}$. The final $\mathrm{pH}$ was $6.5 \pm$ 0.1 when stored at $3^{\circ} \mathrm{C}$.

Veronal buffer. This was prepared by dissolving $11.188 \mathrm{Gm}$. of analytical grade 5,5-diethylbarbituric acid and $82.4 \mathrm{Gm}$. of the sodium salt of this acid in $3,900 \mathrm{ml}$. of $\mathrm{CO}_{2}$-free warm distilled water with final adjustment to a volume of $4,000 \mathrm{ml}$. at $20^{\circ} \mathrm{C}$. This buffer had a specific conductivity of $3.11( \pm 0.05) \times 10^{-3}$ mho and a $\mathrm{pH}$ of $8.65( \pm 0.03)$ at $0^{\circ} \mathrm{C}$.

Apparatus. The fractionation was performed at $-5^{\circ}$ C. in a cold bath of 50 gallon capacity equipped with a pump stirrer and with the temperature regulated to -5.0 $\pm 0.5^{\circ} \mathrm{C} .1$

All centrifugation was with a Servall superspeed refrigerated centrifuge set at $-5^{\circ} \mathrm{C}$. with SS-1 $35^{\circ}$ angle rotor of radius $10.8 \mathrm{~cm}$., providing a relative centrifugal force of $7,710 \times \mathrm{G}$ at $8,000 \mathrm{rpm}$.

Technique of fractionation. After much experimental variation in technique, the following procedure was adopted as the standard. Exactly $1.55 \mathrm{Gm}$. of pooled lyophilized RS-1 solids are suspended in $25 \mathrm{ml}$. of distilled water by gentle stirring for one minute and allowed to stand at $3^{\circ} \mathrm{C}$. overnight. The resulting solution is dark brown in color, but clear. Centrifugation for 20 minutes at $-5^{\circ} \mathrm{C}$. may give a sediment having a lyophilized dry weight approximating 2 to 4 per cent of the original RS-1 solids. The supernate is adjusted to exactly $25 \mathrm{ml}$. at $-5^{\circ} \mathrm{C}$. by addition of distilled water and cooled to approximately $1^{\circ} \mathrm{C}$.

Step 1. Five plastic centrifuge tubes of $40 \mathrm{ml}$. capacity are suspended in the bath and $2 \mathrm{ml}$. of precooled

\footnotetext{
1 American Instrument Company, Bath No. 4-86 G.
} 
TOTAL NONDIALYZABLE SOLIDS

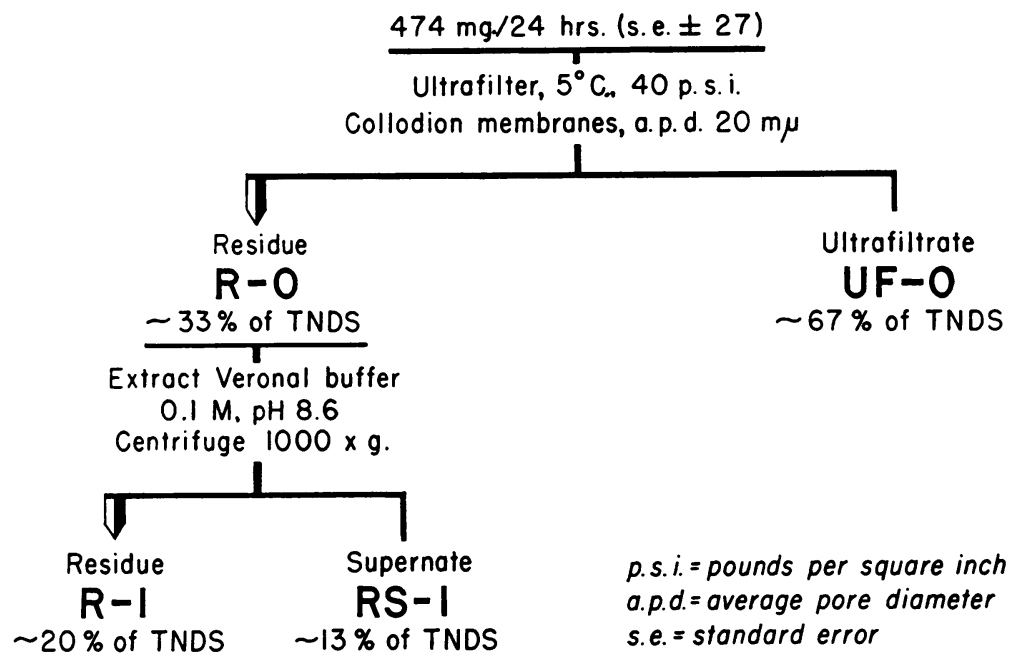

Fig. 1. Flow Sheet Illustrating the Technique for Fractionating Urinary Total Nondialyzable Solids and the Normal Percentage Weight Distribution Among the Fractions After Lyophilization

Reagent I added to each. Five ml. of precooled RS-1 solution is then added dropwise with constant stirring followed by dropwise addition of $18 \mathrm{ml}$. of Reagent $\mathrm{I}$ and continued stirring for 15 minutes. The tubes are then permitted to stand for 60 minutes.

The tubes are transferred directly into the precooled centrifuge and centrifuged for 30 minutes. The clear supernatant solution is removed, pooled and stored in the cold bath at $-5^{\circ} \mathrm{C}$. The dark brown precipitate is returned to the cold bath and resuspended by gentle stirring for 15 minutes in $10 \mathrm{ml}$. of Reagent I. After standing for 15 minutes, the tubes are recentrifuged as above. The clear supernate is combined with the original to give a total volume of $175 \mathrm{ml}$. The residue, designated fraction RS-1A, is taken up in $2 \mathrm{ml}$. of veronal buffer with $1 \mathrm{ml}$. of buffer wash for each tube, giving a final volume of 15 $\mathrm{ml}$. of solution. This material is then subjected to lyophilization after dialysis against distilled water at $3^{\circ} \mathrm{C}$. for 72 hours. The lyophilized material is a white, fluffy, nonhygroscopic powder.

In the initial efforts to fractionate RS-1 solids by the above technique, the precipitation and filtration through sintered glass cups of $14 \mu$ maximal porosity was attempted. ${ }^{2}$ This was unsatisfactory because of the high concentration of mucosubstances in the filtrate. These molecules adhered to the glass, thus blocking the filter pores to such an extent that filtration required 24 to 36 hours at a pressure of $38 \mathrm{~cm}$. of mercury. There was a considerable loss of material by entrapment in the filters, even though much of this material appeared to be quite soluble in the precipitating medium, hence the need for centrifugation rather than filtration in Step 1.

The precipitate RS-1A is comparable to Cohn Fractions I, II and III. Since the quantity of solids in this

\footnotetext{
2 Corning Glass cups, size $\mathbf{M}$.
}

fraction was relatively small and only two concentration gradients were seen by boundary electrophoresis, no further attempts to fractionate RS-1A were made.

Step 2. The supernate from Step 1 (which should total $175 \mathrm{ml}$. at this point) is measured, thoroughly mixed by gentle stirring, and $5.0 \mathrm{ml}$. of zinc reagent added dropwise for each $50 \mathrm{ml}$. of supernate, with constant stirring, at $-5^{\circ}$ C. A greyish-brown flocculent precipitate forms immediately and stirring is continued for 15 minutes. The solution is allowed to stand in the bath for one hour, then transferred to six precooled $40 \mathrm{ml}$. plastic centrifuge tubes and centrifuged for 30 minutes. The clear and colorless supernate is removed and returned to the cold bath. A zinc acetate wash is prepared by addition of $8 \mathrm{ml}$. of zinc reagent to $100 \mathrm{ml}$. of Reagent I. The dark brown precipitate in each tube is resuspended in $15 \mathrm{ml}$. of precooled zinc acetate wash by gentle stirring and, after 15 minutes standing at $-5^{\circ} \mathrm{C}$., the centrifugation is repeated. The clear supernate is combined with that above from the first centrifugation. This supernate, designated fraction RS-1C, is dialyzed against distilled water in preparation for lyophilization. The lyophilized product is a cream-colored, fluffy powder. This fraction is comparable to Cohn Fraction VI. The residues of each tube are taken up in $3 \mathrm{ml}$. of veronal buffer followed by a 2 $\mathrm{ml}$. and $1 \mathrm{ml}$. wash with veronal buffer. The transfer funnel is washed with $1 \mathrm{ml}$. of veronal buffer to give a final volume of $37 \mathrm{ml}$. for the residue, which is completely soluble as a dark brown but clear solution. This fraction, designated fraction RS-1B, is comparable to Cohn Fractions IV and V. This material is dialyzed against distilled water and lyophilized for recovery of the solids. Lyophilization yields a tan, fluffy, nonhygroscopic powder. Analytical methods. Analyses of the lyophilized solids for total nitrogen, hexose, "sialic acid," hexosamine, 
TABLE I

Distribution of recovered solids in fractions of $R S-1$, expressed as per cent of lyophilized dry weights

\begin{tabular}{|c|c|c|c|c|c|c|}
\hline Pool No. & $12^{*}$ & 13 & 14 & 15 & 16 & $\underset{\text { plasma }}{\text { Human }}$ \\
\hline $\begin{array}{l}\text { Fraction } \\
\text { RS-1A } \\
\text { RS-1B } \\
\text { RS-1C }\end{array}$ & $\begin{array}{r}4.3 \\
75.4 \\
20.3\end{array}$ & $\begin{array}{r}1.4 \\
65.8 \\
32.7\end{array}$ & $\begin{array}{r}0.9 \\
68.4 \\
30.8\end{array}$ & $\begin{array}{r}6.4 \\
68.5 \\
25.1\end{array}$ & $\begin{array}{r}3.8 \\
72.3 \\
23.8\end{array}$ & $\begin{array}{r}32.8 \\
65.6 \\
2.2\end{array}$ \\
\hline $\begin{array}{l}\text { Per cent of } \\
\text { total recovered }\end{array}$ & 48 & 57 & 79 & 78 & 52 & \\
\hline RS-1/R-O $\ddagger$ & 0.33 & 0.51 & 0.38 & 0.31 & 0.31 & \\
\hline
\end{tabular}

* Fractions from Pool 12 weighed after recovery from electrophoresis cell.

† Reference 4.

$\ddagger$ Average for 7 pools, 0.36 . $\mathrm{R}-\mathrm{O}$ is the total nonultrafiltrable fraction of TNDS.

hexuronic acid (naphthoresorcinol method) and lipids were by previously described methods $(1,2)$. Sulfhydryl analyses were by the method of Ellman (5).

\section{RESULTS}

The electrophoretic analysis of RS-1 and of the three subfractions will be presented in a subsequent report.

Table I presents the percentage distribution by weight of the recovered solids in each fraction, the total recovery in terms of per cent of initial lyophilized RS-1 solids, and the ratio of RS-1 to
R-O solids in each of five pools (representing 162 individual 24 hour urine volumes).

Table II presents some analytical results with fractions from three pools of RS-1. These pools were collected during the months of December through February for Pool 13, March through May for Pool 14 and June through July for Pool 15 as a part of the program for evaluation of seasonal variations in urinary TNDS excretion. After correction for loss during fractionation, the sums of the glucides, protides $(\mathrm{N} \times 6.25)$ and total lipids in each fraction account approximately

TABLE II

Analyses of starting samples of RS-1 and of their respective Cohn fractions, expressed as per cent of lyophilized dry weight

\begin{tabular}{|c|c|c|c|c|c|c|c|c|c|c|c|}
\hline \multirow[b]{2}{*}{ Fraction } & \multirow{2}{*}{$\begin{array}{l}\text { Pool } \\
\text { No. }\end{array}$} & \multicolumn{2}{|c|}{ Hexose* } & \multirow{2}{*}{$\begin{array}{l}\text { "Sialic } \\
\text { acid" }\end{array}$} & \multirow{2}{*}{$\begin{array}{c}\text { Hexosa- } \\
\text { mine† }\end{array}$} & \multirow{2}{*}{$\begin{array}{l}\text { Hexu- } \\
\text { ronic } \\
\text { acid } \ddagger\end{array}$} & \multirow[b]{2}{*}{$\mathrm{N}$} & \multirow{2}{*}{$\begin{array}{l}\text { Total } \\
\text { lipids\$ }\end{array}$} & \multirow{2}{*}{$\begin{array}{l}\text { Total } \\
\text { phospho- } \\
\text { lipids }\end{array}$} & \multirow{2}{*}{$\begin{array}{l}\text { Total fatty } \\
\text { acids plus } \\
\text { unsaponi- } \\
\text { fiable } \\
\text { material\| }\end{array}$} & \multirow{2}{*}{$\begin{array}{l}\text { Total } \\
\text { choles- } \\
\text { terol }\end{array}$} \\
\hline & & Anthrone & Orcinol & & & & & & & & \\
\hline Total (RS-1) & $\begin{array}{l}13 \\
15\end{array}$ & $\begin{array}{l}11.7 \\
13.0 \\
(12.2) \rrbracket\end{array}$ & $\begin{array}{c}11.3 \\
9.1 \\
(10.9)\end{array}$ & $\begin{array}{c}5.2 \\
2.6 \\
(1.7)\end{array}$ & $\begin{array}{c}8.9 \\
7.5 \\
(7.8)\end{array}$ & 0.21 & $\begin{array}{l}10.6 \\
10.6\end{array}$ & & & & \\
\hline RS-1A & $\begin{array}{l}13 \\
15\end{array}$ & $\begin{array}{c}9.2 \\
11.8 \\
(11.3)\end{array}$ & $\begin{array}{c}6.5 \\
8.9 \\
(9.9)\end{array}$ & $\begin{array}{c}0.0 \\
0.0 \\
(0.0)\end{array}$ & $\begin{array}{c}5.1 \\
3.6 \\
(3.8)\end{array}$ & & $\begin{array}{r}9.0 \\
11.6\end{array}$ & & & & \\
\hline RS-1B & $\begin{array}{l}13 \\
14 \\
15\end{array}$ & $\begin{array}{c}7.9 \\
8.8 \\
9.8 \\
(6.0)\end{array}$ & $\begin{array}{c}5.1 \\
5.3 \\
6.4 \\
(5.3)\end{array}$ & $\begin{array}{c}0.0 \\
0.0 \\
4.7 \\
(3.5)\end{array}$ & $\begin{array}{c}5.7 \\
5.5 \\
5.0 \\
(7.7)\end{array}$ & 0.18 & $\begin{array}{l}11.5 \\
11.7 \\
11.8\end{array}$ & $\begin{array}{l}9.84 \\
12.2\end{array}$ & $\begin{array}{l}0.38 \\
0.63\end{array}$ & $\begin{array}{l}4.70 \\
3.60\end{array}$ & $\begin{array}{l}0.67 \\
1.01\end{array}$ \\
\hline RS-1C & $\begin{array}{l}13 \\
14 \\
15\end{array}$ & $\begin{array}{c}20.4 \\
24.2 \\
22.0 \\
(24.1)\end{array}$ & $\begin{array}{c}13.7 \\
18.8 \\
20.0 \\
(20.0)\end{array}$ & $\begin{array}{c}7.8 \\
6.8 \\
9.0 \\
(7.3)\end{array}$ & $\begin{array}{l}14.5 \\
15.4 \\
13.0 \\
(13.5)\end{array}$ & & $\begin{array}{l}9.5 \\
7.3 \\
8.0\end{array}$ & $\begin{array}{r}7.86 \\
14.77\end{array}$ & $\begin{array}{l}0.27 \\
0.29\end{array}$ & 4.97 & $\begin{array}{l}0.15 \\
0.43\end{array}$ \\
\hline
\end{tabular}

* Standard was galactose and mannose, $1: 1$ by weight.

$\dagger$ Expressed as glucosamine $\mathrm{HCl}$.

\#aphthoresorcinol method.

\$ Chloroform extract. Insufficient A fraction was obtained to permit lipid analysis.

Petroleum ether extract after saponification.

Tी Figures in parentheses are analyses obtained after redialysis and relyophilization of sample of Pool 15. 
for their respective contributions to the composition and weight of RS-1 solids (2).

The isoelectric precipitation of the total RS-1B was complete within the $\mathrm{pH}$ range of 4.0 to 4.2 . The RS-1C fraction behaved as a mixture of substances with isoelectric points varying between $\mathrm{pH} 2.2$ and 3.5 , although precipitation was never complete between the range 1.0 to 10.0

Both intact and hydrolyzed RS-1 solids contained less than 0.1 per cent sulfhydryl sulfur.

\section{DISCUSSION}

The system of fractionation used here requires critical control of $\mathrm{pH}$, temperature, ionic strength and zinc concentrations. Deviations in technique to improve the rate of recovery are hence limited in scope. The precipitated mucosubstances tend to adhere to glass and even plastic surfaces so tenaciously that they cannot be removed by rinsing with the precipitating medium. In separate experiments these invisible films were recovered from the stirring rods and other apparatus by copious distilled water rinses which were subsequently lyophilized and weighed. The mechanical loss thus determined under optimum conditions was approximately 0.6 per cent of the 1.55 $\mathrm{Gm}$. of starting solids.

The lyophilized RS-1 solids contained approximately 2 per cent of insoluble material which was lost in the initial centrifugation; this is not necessarily denatured protein, but may instead be traces of incompletely separated fraction R-1 (2). After lyophilization, approximately 4 per cent of RS-1 became dialyzable. It was found possible to increase the percentage of recovered solids to 89 per cent of the starting total by removing these substances in the initial step of this procedure. This was readily accomplished by redialysis of the aqueous suspension of RS-1 prior to the initial precipitation, but had the disadvantage that approximately half of the mucosubstances of $\mathrm{RS}-1 \mathrm{~B}$ then appeared in the RS-1A precipitate.

This change of some component(s) of RS-1 from nondialyzable to dialyzable form (or other source of loss) apparently involves fractions RS$1 \mathrm{~B}$ and RS-1C to an approximately equal extent, otherwise the proportions of these two fractions should vary with the per cent of total recovery. The proportional relationship among the three fractions was far more constant than the total recovery (Table I). Electrophoretic studies of RS-1 indicated the alpha components and the immobile component to be quantitatively the most variable (3). The former appear in both RS-1B and RS-1C, the latter in RS-1C only.

We have been unable to detect any seasonal variation in the amount or composition of RS-1 urinary solids.

The data of Table II demonstrate some chemical differences in the three fractions. The glucide content suggests a high concentration of mucosubstances in all fractions, being much the greatest relative to nitrogen content in RS-1C.

The detection of hexuronic acid only in the RS-1B solids is not evidence that it is absent from RS-1C. The hydrolytic conditions for the method used here are inadequate to release the hexuronic acid from (e.g.) chondroitin sulfuric acid (2), while interference prevents a reliable determination by the carbazole technique. Paper electrophoresis of these fractions, with commercial chondroitin sulfate as a control and color development with aqueous toluidine blue $\mathrm{O}$, indicated the presence of metachromatic material with the mobility of chondroitin sulfate. The majority of this material appeared in RS-1B, although a trace was consistently present in RS-1C and none was detected in RS-1A. There was a suggestion that more than one metachromatic substance was present but trailing prevented a clear evaluation of the number of components.

The absence of sulfhydryl groups after hydrolysis of RS-1 solids is an indication of the absence of sulfur-containing amino acids. This, together with the low isoelectric points, the relatively high carbohydrate contents and the low albumin to "globulin" ratio is further evidence that materials having electrophoretic mobilities at $\mathrm{pH} 8.6$ like serum globulins are chiefly mucosubstances and not primarily proteins which have escaped into the urine. The results of a number of other workers indicate that the situation is probably quite different with certain pathological urines [e.g., (6)].

The results of Webb, Rose and Sehon $(7,8)$ indicate that the mucosubstances of RS-1 have molecular weights on the order of 10,000. This would be consistent with current ideas concerning the general relationship between molecular 
size and selective appearance of materials in the urine. However, these workers are dealing with a combination of both the RS-1 and UF-O portions of the TNDS, which makes it difficult to compare their results with our own.

Total cholesterol in RS-1C was lower than in RS-1B. Values for "total lipids" and "fatty acids plus unsaponifiable matter" were of the same order of magnitude in the two subfractions and were also similar to, or only somewhat lower than, the values previously determined on the unfractionated material, RS-1 (2). However, in both subfractions figures for "total phospholipids" were considerably smaller than in RS-1 (onehalf to one-eighth in RS-1B, and one-fourth to one-tenth in RS-1C), a finding which definitely suggests that phospholipids are to a large extent split and/or removed during the separation procedure. $^{3}$

\section{SUMMARY}

The nonultrafiltrable, buffer-soluble fraction (fraction RS-1) of the total nondialyzable solids of normal human urine was subjected to the first steps of Cohn's Method 10 for the separation of plasma proteins. Three distinctly different and

3 The low phospholipid values and the sizable differences between the "total lipids" and the "total fatty acids plus unsaponifiable matter" indicate that the chloroform extracts of RS-1B and RS-1C included substances other than phospholipids, which were insoluble in petroleum ether or which, upon saponification, yielded a large proportion of products insoluble in this solvent. Some of these products might be hydroxyacids resulting from the oxidation of unsaturated fatty acids in the course of the manipulations. On the other hand, from the acidimetric titration of the petroleum ether extracts and from the weight of these extracts (corrected for the weight of cholesterol) the maximum possible values for the average molecular weight of fatty acids can be calculated. The figures so obtained (201 for RS-1B, Pool 13; 241 for RS-1B, Pool 14; and 232 for RS-1C, Pool 13) are distinctly below the corresponding values for the mixtures of fatty acids extracted from serum or tissues (276 to 284) and therefore suggest the presence of some organic acid soluble in petroleum ether, but with a rather short carbon chain and relatively nonvolatile. apparently reproducible fractions were obtained. It has not been possible to separate mucosubstances from proteins by this method. The low isoelectric points, high glucide content and absence of sulfhydryl groups suggest that the RS-1 solids are composed almost entirely of mucosubstances.

\section{ACKNOWLEDGMENT}

The authors wish to acknowledge the technical assistance of Mrs. Phyllis Tilley and Miss Emily Angell.

\section{REFERENCES}

1. King, J. S., Jr., Boyce, W. H., Little, J. M., and Artom, C. Total nondialyzable solids (TNDS) in human urine. I. The amount and composition of TNDS from normal subjects. J. clin. Invest. 1958, 37, 315.

2. Boyce, W. H., King, J. S., Jr., Little, J. M., and Artom, C. Total nondialyzable solids (TNDS) in human urine. II. A method for reproducible fractionation. J. clin. Invest. 1958, 37, 1658.

3. Boyce, W. H., Garvey, F. K., and Norfleet, C. M., Jr. Proteins and other biocolloids of urine in health and in calculous disease. I. Electrophoretic studies at $\mathrm{pH} 4.5$ and 8.6 of those components soluble in molar sodium chloride. J. clin. Invest. 1954, 33, 1287.

4. Lever, W. F., Gurd, F. R. N., Uroma, E., Brown, R. K., Barnes, B. A., Schmid, K., and Schultz, E. L. Chemical, clinical, and immunological studies on the products of human plasma fractionation. XL. Quantitative separation and determination of the protein components in small amounts of normal human plasma. J. clin. Invest. 1951, 30, 99.

5. Ellman, G. L. A colorimetric method for determining low concentrations of mercaptans. Arch. Biochem. 1958, 74, 443.

6. Slater, R. J., and Kunkel, H. G. Filter paper electrophoresis with special reference to urinary proteins. J. Lab. clin. Med. 1953, 41, 619.

7. Webb, T., Rose, B., and Sehon, A. H. Biocolloids in normal human urine. I. The amount and electrophoretic characteristics. Canad. J. Biochem. 1958, 36, 1159.

8. Webb, T., Rose, B., and Sehon, A. H. Biocolloids in normal human urine. II. Physiochemical and immunochemical characteristics. Canad. J. Biochem. 1958, 36, 1167. 